OPEN ACCESS

Edited by:

Barbara Bottazzi,

University of Milan, Italy

Reviewed by:

Taruna Madan,

National Institute for Research in

Reproductive Health (ICMR), India

Remo Castro Russo,

Federal University of Minas Gerais,

Brazil

*Correspondence:

Roberto Ronca

roberto.ronca@unibs.it

Marco Presta

marco.presta@unibs.it

${ }^{\dagger}$ These authors share first authorship

Specialty section:

This article was submitted to Molecular Innate Immunity, a section of the journal

Frontiers in Immunology

Received: 15 October 2020

Accepted: 11 January 2021

Published: 18 February 2021

Citation:

Maccarinelli F, Bugatti M, Churruca Schuind A, Ganzerla S, Vermi $W$, Presta $M$ and Ronca $R$ (2021) Endogenous Long Pentraxin 3 Exerts a Protective Role in a Murine

Model of Pulmonary Fibrosis.

Front. Immunol. 12:617671. doi: 10.3389/fimmu.2021.617671

\section{Endogenous Long Pentraxin 3 Exerts a Protective Role in a Murine Model of Pulmonary Fibrosis}

\author{
Federica Maccarinelli ${ }^{1 \dagger}$, Mattia Bugatti ${ }^{1,2 \dagger}$, Ander Churruca Schuind ${ }^{1}$, Sara Ganzerla ${ }^{2}$, \\ William Vermi ${ }^{1,2}$, Marco Presta $^{1 *}$ and Roberto Ronca ${ }^{1 *}$ \\ ${ }^{1}$ Department of Molecular and Translational Medicine, University of Brescia, Brescia, Italy, ${ }^{2}$ ASST Spedali Civili di Brescia, \\ Brescia, Italy
}

Pulmonary fibrosis is a progressive scarring disease of the lungs, characterized by inflammation, fibroblast activation, and deposition of extracellular matrix. The long pentraxin 3 (PTX3) is a member of the pentraxin family with non-redundant functions in innate immune responses, tissue repair, and haemostasis. The role played in the lungs by PTX3 during the fibrotic process has not been elucidated. In this study, the impact of PTX3 expression on lung fibrosis was assessed in an intratracheal bleomycin (BLM)-induced murine model of the disease applied to wild type animals, transgenic mice characterized by endothelial overexpression and stromal accumulation of PTX3 (Tie2-PTX3 mice), and genetically deficient $P t x 3^{-/-}$animals. Our data demonstrate that PTX3 is produced during BLM-induced fibrosis in wild type mice, and that PTX3 accumulation in the stroma compartment of Tie2-PTX3 mice limits the formation of fibrotic tissue in the lungs, with reduced fibroblast activation and collagen deposition, and a decrease in the recruitment of the immune infiltrate. Conversely, Ptx3-null mice showed an exacerbated fibrotic response and decreased survival in response to BLM treatment. These results underline the protective role of endogenous PTX3 during lung fibrosis and pave the way for the study of novel PTX3-derived therapeutic approaches to the disease.

Keywords: long pentraxin-3, lung fibrosis, bleomycin, stroma, fibroblast, immune infiltrate

\section{INTRODUCTION}

Pulmonary fibrosis (PF) includes more than 200 different pathological conditions characterized by inflammation and scar tissue formation in the lungs. PF can be grouped in five categories: druginduced, radiation-induced, environmental, autoimmune, and occupational (1). However, the most common type of PF is represented by the "Idiopathic Pulmonary Fibrosis" (IPF), whose etiology remains unknown. In the last years, the incidence of IPF has increased over time in most countries worldwide, with approximately 50,000 new cases diagnosed each year in the U.S (2).

Starting symptoms of IPF, such as shortness of breath, dry hacking cough and fatigue, get significantly worse when the deposition of scar tissue augments, increases in stiffness and causes an irreversible loss of pulmonary functionality (3).

Despite the unknown cause(s) of IPF, aging (IPF is rare before 50 years of age), cigarette smoking, and genetic predisposition may represent relevant risk factors $(4,5)$. At histopathological 
level, IPF appears as a progressive scarring disease in the lungs, characterized by injury and hyperplasia of alveolar epithelial cells and fibroblasts, accumulation of inflammatory cells, consistent deposition of extracellular matrix (ECM), and formation of scars (6). Particular attention has been given to the onset of an inflammatory response and to the presence of an immune infiltrate that establishes and sustains a damaging and fibrotic context in the lungs (7). Even though little is known about the role of monocytes and tissue-resident macrophages in lung fibrosis (8), macrophages are persistently increased in the lung in close proximity to collagen-producing fibroblasts, in keeping with the role exerted by monocytes in the development of experimental fibrosis $(9,10)$. In particular, M2 macrophages accumulating in the lungs during fibrogenesis have been identified as the major source of several pro-fibrotic mediators, which stimulate fibroblast proliferation and collagen synthesis/ deposition (11-14).

Different in vivo animal models of PF have been developed to understand the evolution of fibrotic responses in the lungs and in other organs (15), allowing the identification of cell types, mediators, and processes that are likely involved also in the human disease. To date, bleomycin (BLM)-induced pulmonary fibrosis in mice represents the best characterized murine model to study PF and IPF $(15,16)$. BLM is an antibiotic efficacious for the treatment of squamous cell carcinomas and skin tumors, but with limiting and dose-dependent pulmonary toxicity that results in progressive fibrosis (17). In mice, a single (or multiple, according to the specific schedule) intratracheal administration of BLM causes lung injury, resulting in pulmonary fibrosis that can be observed by day $14(15,18-20)$. The initial direct damage to alveolar epithelial cells is followed by dense ECM deposition associated with vessel remodeling and intense inflammatory infiltration, mimicking what is observed in patients (15).

The soluble pattern recognition receptor long pentraxin-3 (PTX3) is a member of the pentraxin family and a component of the humoral arm of the innate immunity. PTX3 expression is normally low in tissues and serum under physiological conditions, but the levels of PTX3 quickly rise in the presence of inflammatory and/or infectious stimuli due to its local production by different cell types, such as infiltrating immune cells, endothelial cells, and other stromal components (21). PTX3 exerts its function by binding to different ligands, including growth factors, microbial moieties, complement components, and ECM proteins (22-24). PTX3 has been reported to be upregulated and to play a protective role in various lung diseases (21). In lung infections, the protective function of PTX3 has been described in different pathological settings, including aspergillosis (25), pneumonia (26), and severe acute respiratory syndrome (27). In acute lung injury, which is strictly associated with activation of innate immune responses in the lungs, PTX3 deficiency in Ptx3 null mice results in increased sensitivity to lung tissue damage after exposition to LPS (28). Finally, PTX3 has been proposed as a possible biomarker of disease in acute lung injury and other pulmonary disorders, including asthma, and lung carcinoma (28-30).

In the present study, we investigated the impact of endogenous PTX3 in a BLM-induced murine model of lung fibrosis. Our data show that pulmonary PTX3 expression is upregulated during lung fibrosis. In addition, by using both transgenic PTX3-overexpressing mice and Ptx3 null animals, we demonstrate that endogenous PTX3 exerts a protective effect in BLM-induced lung fibrosis.

\section{MATERIALS AND METHODS}

\section{Bleomycin-Induced Pulmonary Fibrosis}

Animal experiments were approved by the local animal ethics committee (OPBA, Organismo Preposto al Benessere degli Animali, Università degli Studi di Brescia, Italy) and were performed in accordance with national guidelines and regulations. Procedures involving animals and their care conformed with institutional guidelines that comply with national and international laws and policies (EEC Council Directive 86/609, OJ L 358, 12 December 1987) and with "ARRIVE" guidelines (Animals in Research Reporting In Vivo Experiments). Eight weeks old wild type (WT) C57BL/6, Ptx $3^{-1-}$ (31) and Tie2-PTX3 (32) male mice received a single, slow intratracheal injection of 4.0 $\mathrm{mg} / \mathrm{kg}$ bleomycin (B2434 Sigma-Aldrich) dissolved in $30 \mu \mathrm{l}$ of phosphate-buffered saline (PBS). Body weight variations were monitored throughout the whole experimental period (Supplementary Figure S1). Mice were sacrificed at different time points $(14,21$, and 28 days after treatment), and lungs collected and prepared for histopathological analysis. For each time point 5-8 mice were used for each strain (WT, Tie2-PTX3, and $P t \times 3^{-/-}$animals).

\section{Histopathological Analysis}

The left lung was fixed overnight in $10 \%$ formalin $(05-01004 \mathrm{~F}$ BioOptica), dehydrated in a graded ethanol series, embedded in paraffin and cut into $4-\mu \mathrm{m}$ sections. Pulmonary fibrosis was analyzed using digital microscopy. For the analysis of the fibrosis area, sections were stained with Masson's trichrome, digitalized by AperioScanScope CS Slide Scanner (Leica Biosystem, New Castle Ltd, UK) at 40x magnification and submitted to ImageScope software (Leica).

\section{Immunohistochemistry}

Paraffin-embedded lung tissues were prepared as previously described (33). Four- $\mu \mathrm{m}$ sections were deparaffinized with xylene, incubated with $3 \% \mathrm{H}_{2} \mathrm{O}_{2}$ in methanol for $30 \mathrm{~min}$ to inhibit endogenous peroxidase activity and then re-hydrated. Immunostaining was performed upon microwave or thermostat bath oven epitope retrieval in ethylene diamine tetra-acetic acid (EDTA) buffer ( $\mathrm{pH} 8.00$ ). The following primary antibodies were used: rabbit polyclonal anti-PTX3 (kind gift of B. Bottazzi, Humanitas Clinical Institute-Milan 1:100), mouse monoclonal anti- $\alpha$-SMA antibody (clone 1A4, 1:300, Biocare, \# CM001), rat monoclonal anti-CD45 (clone 30-F11, 1:100, BD Pharmingen, \#553076), rabbit polyclonal anti-IBA1 (1:300, Wako, 019-19741), rat monoclonal anti-Ly6G (clone 1A8, 1:400, Cederlane, \#ABF118UD), mouse monoclonal anti-CD3 (clone SP7, 1:70, Leica, \#565-LCE) and rabbit monoclonal PECAM-1 (clone M-20, 
1:200, Santa Cruz, \#SC-1506). Immunoreaction was revealed by using EnVision+ System-HRP Labelled Polymer anti-mouse or anti-rabbit (Dako) or using Rat-on-Mouse HRP-Polymer (Biocare Medical) followed by $\mathrm{DAB}$ as chromogen: sections were counterstained with hematoxylin. Immunostained slides were digitalized as described above and evaluated using Positive Pixel Count v9 9.0 Algorithm (Imagescope, Leica Biosystem). Staining was graded for positive pixel density (0 indicating $<25,000 / \mathrm{mm}^{2} ; 1,<50,000 / \mathrm{mm}^{2} ; 2,<100,000 / \mathrm{mm}^{2} ; 3>100,000 /$ $\mathrm{mm}^{2}$ positive pixel). It must be pointed out that physiological $\alpha$-SMA immuno-reactivity in perivascular and peri-bronchiolar areas was excluded in the evaluation of the samples.

\section{Hydroxyproline Quantification in Lungs}

The right upper lung lobes were homogenized in $\mathrm{ddH}_{2} \mathrm{O}(10 \mathrm{mg}$ of tissue in $100 \mu \mathrm{l})$. Then an aliquot was hydrolyzed in $\mathrm{HCl} 6 \mathrm{M}$ at $105^{\circ} \mathrm{C}$ for $3 \mathrm{~h}$ and centrifuged at 13,000 rpm for $5 \mathrm{~min} .5 \mu \mathrm{l}$ of the supernatant were pipetted in triplicate onto a 96 well plate and incubated at $60^{\circ} \mathrm{C}$ for $1 \mathrm{~h}$. Collagen content was assessed using a Hydroxyproline Colorimetric Assay Kit (MAK008 SigmaAldrich) according to the manufacturer's instructions.

\section{RNA Extraction and qPCR}

Total RNA was isolated from right lower lung using TRIzol Reagent (Invitrogen) according to the manufacturer's instructions. Two $\mu \mathrm{g}$ of total RNA were retro-transcribed with MMLV reverse transcriptase (Invitrogen) using random primers. cDNA was analyzed by quantitative real-time polymerase chain reaction (qPCR) analysis. Beta-Actin (ActB) was used as housekeeping gene for normalization. Primers used: Mm_Ptx3 forward: 5'-GACCTCGGATGACTACGAG-3' , reverse: 5' -CTC CGAGTGCTCCTGGCG-3'; CollA1 for: 5'-TGCTCCTCTTAG GGGCCACT-3', rev: 5'-ATTGGGGACCCTTAGGCCATT-3'; Col1A2 for: 5'-GGTGAGCCTGGTCAAACGG-3', rev: 5' -ACT GTGTCCTTTCACGCCTTT-3'; Col3A1for: 5'-CTGTAACATG GAAACTGGGGAAA-3', rev: 5'-CCATAGCTGAACTGAAA ACCACC-3'; Acta2 for: 5'-TGCTGACAGAGGCACCACTG AA-3', rev: 5'-CAGTTGTACGTCCAGAGGCATAG-3'; ActB for: 5'-CTGTCGAGTCGCGTCCACC-3', rev: 5' -ATCGT CATCCATGGCGAACTG-3'.

\section{Statistical Analyses}

T-test for unpaired data (2-tailed) was used to test the probability of significant differences between two groups of samples. For the statistical analysis the WT group at day 0 was used as reference. The following abbreviations were used for the indication of significance: ${ }^{*} \mathrm{p}<0.05 ;{ }^{* *} \mathrm{p}<0.01 ;{ }^{* *} \mathrm{p}<0.001$.

\section{RESULTS}

\section{PTX3 Is Modulated During BLM-Induced Lung Fibrosis}

Intratracheal administration of BLM induces peri-bronchial lung fibrosis in mice, detectable 14 days after treatment and progressing up to day 21, to decrease at/after day 28 (15).
On this basis, in order to evaluate the modulation of PTX3 expression in the lungs during fibrosis onset, C57BL/6 male mice were treated intratracheal with BLM and sacrificed after 14, 21, and 28 days. Then, harvested lungs were processed for immunohistochemical (IHC) and qPCR analyses. In keeping with its role as an "early" response to damaging and inflammatory stimuli (21), PTX3 immuno-reactivity was significantly increased in fibrotic lung sections 14 days after BLM treatment, to decrease to basal levels at day 28 (Figures 1A, B). These data were confirmed by qPCR analysis that demonstrated a significant upregulation of Ptx3 expression at day 14 and its gradual decrease thereafter (Figure 1C).

\section{PTX3 Exerts a Protective Role in Lung Fibrosis}

Previous observations had shown a potential role of PTX3 as a protective factor in different pathological settings in the lungs (21). On this basis, we evaluated the impact of PTX3 overexpression during the onset and progression of the fibrotic process in the lungs by taking advantage of a transgenic Tie2PTX3 murine model. In this model the overexpression of the human PTX3 gene (Supplementary Figure S2) is driven by the endothelial-specific Tie2 promoter, leading to the stromal accumulation of high levels of the PTX3 protein in all tissues, including the lungs, without any significant impact on normal development of organs and tissues $(32,34)$. Wild type (WT) and

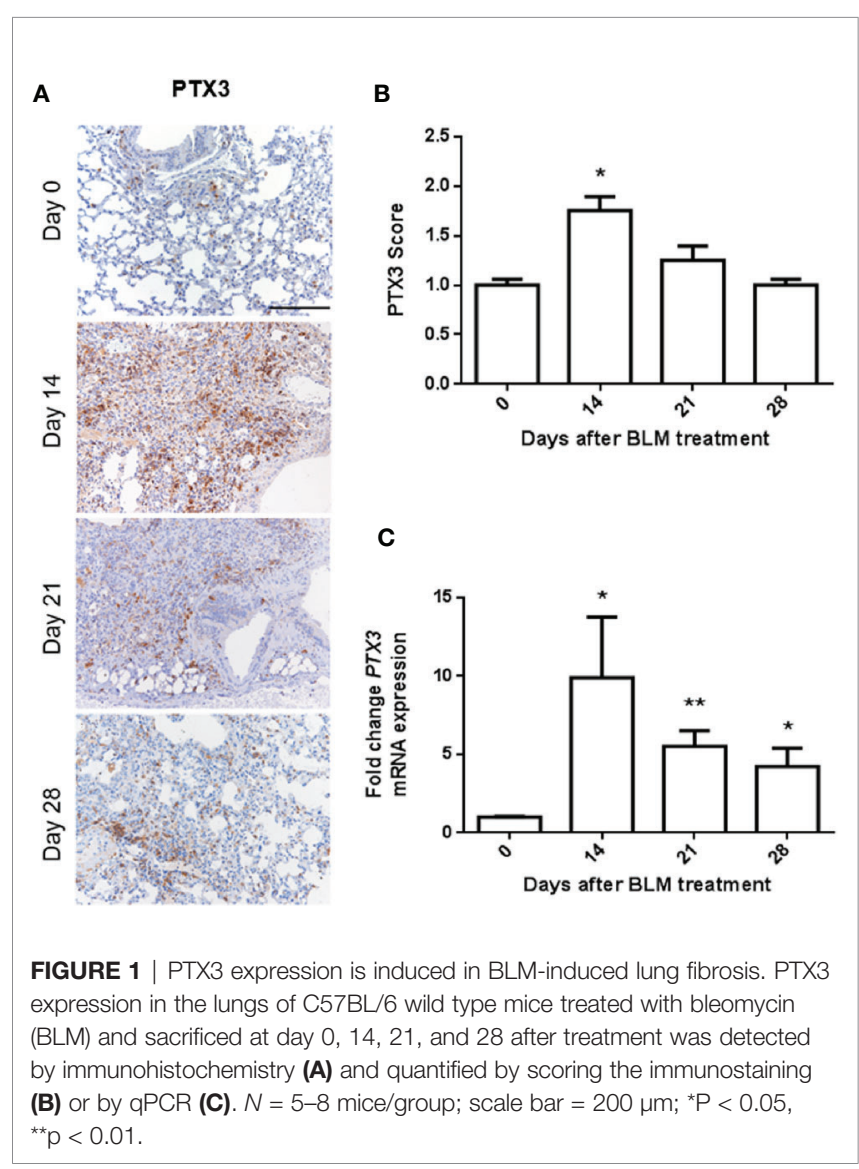


transgenic Tie2-PTX3 mice were treated intratracheal with BLM and the progression of lung fibrosis was investigated. As shown in Figures 2A, B, quantification of fibrotic/collagen positive areas after trichrome staining of lung sections revealed an increase of fibrotic tissue in WT animals from day 14 to day 21 , with a partial regression at day 28 . When compared to WT mice, fibrotic areas were significantly reduced in Tie2-PTX3 mice at all the time points investigated, close to the levels measured in untreated animals. Accordingly, the levels of hydroxyproline, a marker for the presence of collagen in the ECM, were significantly higher in WT lungs when compared with those measured in Tie2-PTX3 animals (Figure 2C).

Further characterization of BLM-treated lungs showed a significant increase of areas with alpha-smooth muscle actin $\left(\alpha \mathrm{SMA}^{+}\right)$positive fibroblasts in WT mice when compared with Tie2-PTX3 animals (Figures 3A, B). Related to this fibroblastic reaction, upregulation of the expression of Col1a1, Col1a2, and Col3a1 collagen subunits and of the $\alpha$ SMA-encoding Acta2 gene was detected by qPCR in the lungs of WT but not of Tie2-PTX3 mice (Figure 3C). In addition, foci of angiogenesis, represented by $\mathrm{CD}_{3} 1^{+}$endothelial cells, were detectable in the fibrotic areas of BLM-treated mice with no apparent difference between WT and Tie2-PTX3 groups (Supplementary Figure S3).

The inflammatory infiltrate plays a pivotal role during the response to tissue damage that drives fibrosis $(7,8)$. In order to quantify the overall immune infiltrate in BLM-treated lungs, CD45 immunostaining was performed on samples from the different groups. As shown in Figure 4A, a vast $\mathrm{CD}_{4} 5^{+}$cell infiltrate was detected in WT lungs, while a significant reduction of $\mathrm{CD}_{4} 5^{+}$cells was observed in Tie2-PTX3 lungs at all the time points investigated. These observations are in line with the limited fibrotic response occurring in Tie2-PTX3 animals. Accordingly, in keeping with the pivotal role played by macrophages in BLM-induced fibrosis (7), $\mathrm{IBA}^{+}$macrophages were widely present in fibrotic WT lungs throughout the whole experimental period and consistently reduced in Tie2-PTX3 lungs that showed a detectable macrophagic infiltrate only ad day 14 (Figure 4B). In addition, a further characterization of the immune infiltrate at the time points considered demonstrate that $\mathrm{CD}^{+}$lymphocytes increase in both WT and Tie2-PTX3 at day 14 after treatment, to decrease more rapidly in PTX3 overexpressing animals in respect to controls (Supplementary Figure S4A). Finally, very few $\mathrm{Ly}_{6 \mathrm{G}}{ }^{+}$neutrophils were present in the lungs of treated mice, with no significant differences between the WT and Tie2-PTX3 animals (Supplementary Figure S4B).

Together, these data indicate that PTX3 overexpression exerts a protective impact on BLM-induced fibrosis in transgenic Tie2PTX3 mice. These findings, together with the observation that a significant upregulation of PTX3 expression occurs in WT animals during BLM-induced fibrosis (see above), prompted us to assess the role, if any, of endogenous PTX3 on this process. To this aim, we took advantage from genetically deficient $P t \times 3^{-1-}$ mice that lack endogenous PTX3 expression in all organs, including lungs, and are characterized by a normal pre and post-natal development with no signs of inherited pathological conditions with the exception of subfertility in

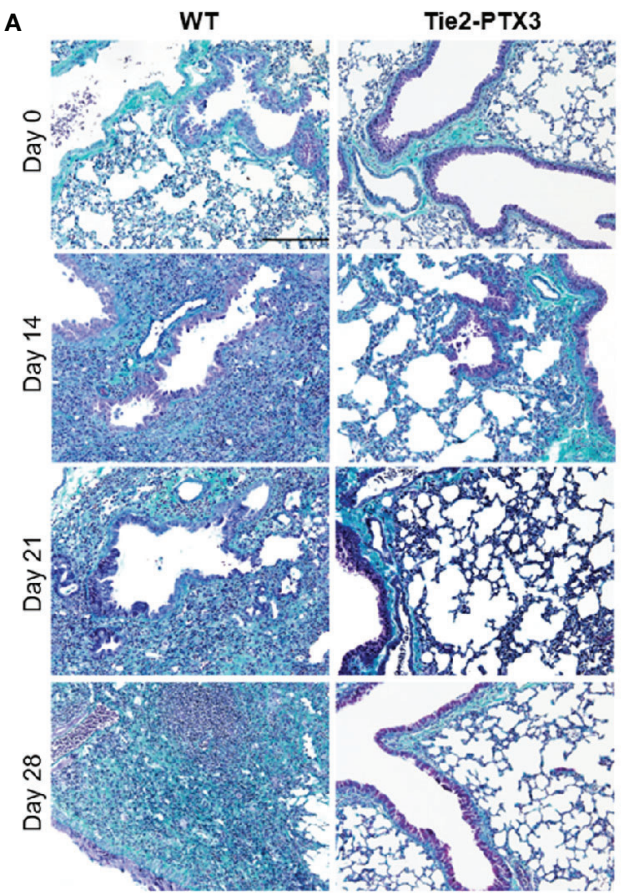

B

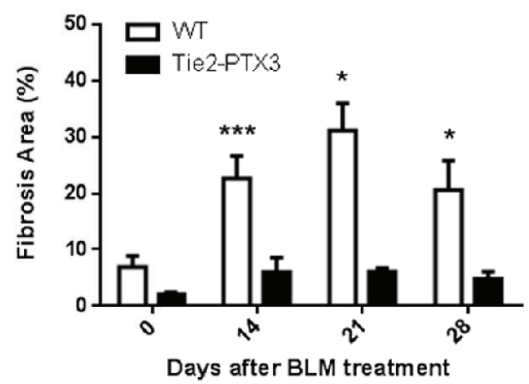

C

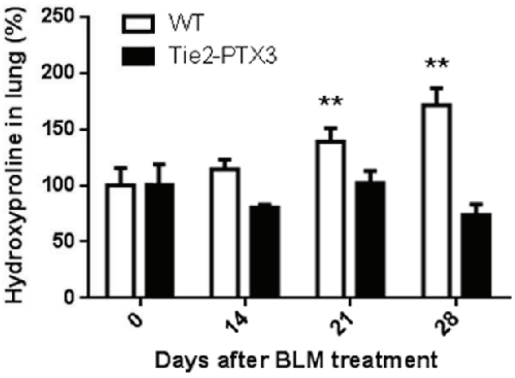

FIGURE 2 | Stromal PTX3 overexpression prevents lung fibrosis in BLM-treated mice. Fibrosis in lungs of wild type (WT) and transgenic Tie2-PTX3 mice treated with bleomycin (BLM) was determined by Masson's trichrome staining (A), subsequent quantification of fibrotic area (B), and quantification of hydroxyproline in lungs extracts (C). $N=5-8$ mice/group; scale bar $=200 \mu \mathrm{m} ;{ }^{*} \mathrm{P}<0.05,{ }^{* \star} \mathrm{p}<0.01,{ }^{\star \star \star} \mathrm{p}<0.001$ 
A

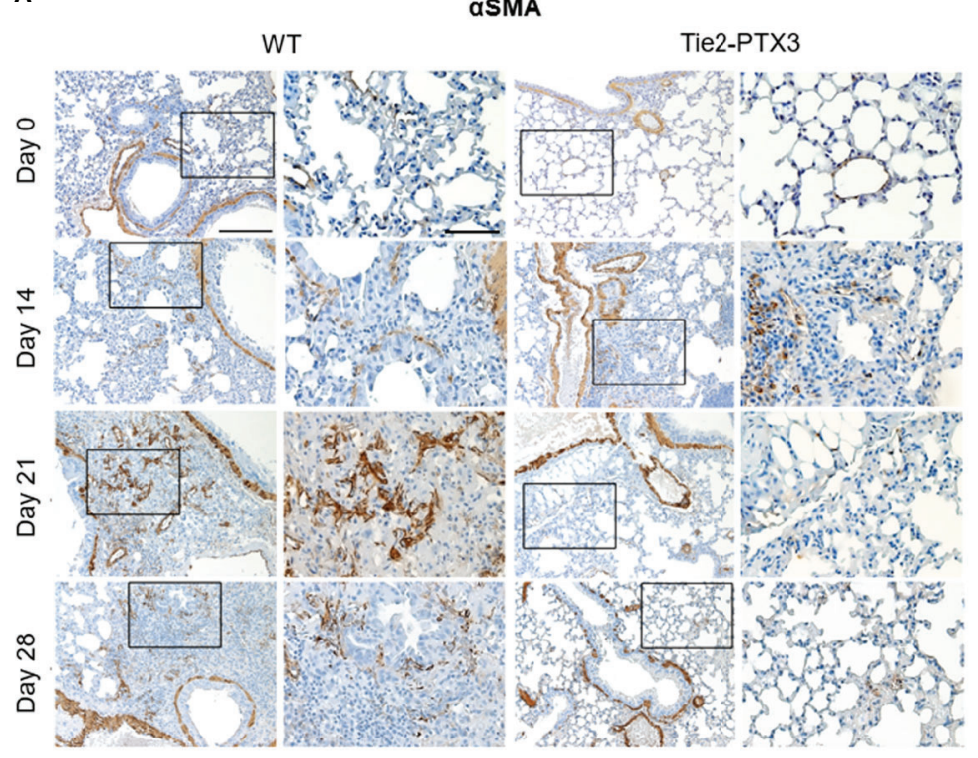

B
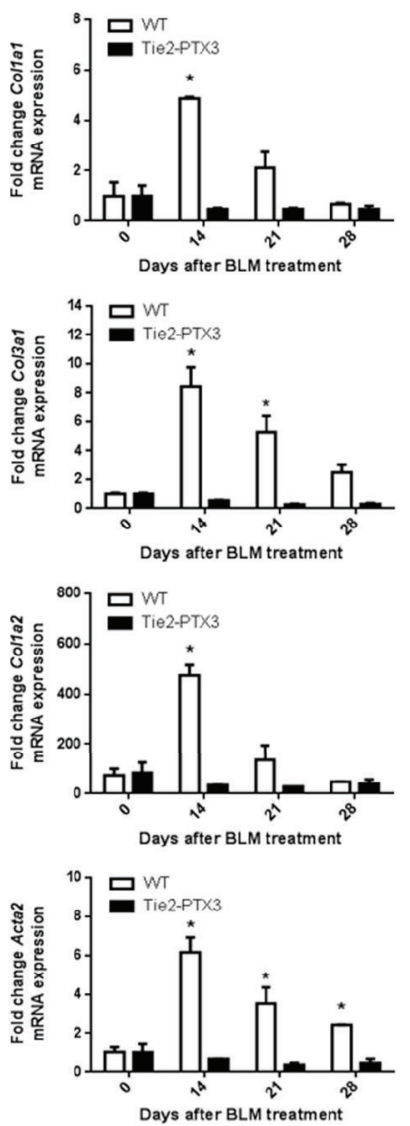

FIGURE 3 | Stromal PTX3 overexpression reduces fibroblast activation in BLM-induced lung fibrosis. (A) Immunohistochemical analysis of $\alpha$ SMA expression in the lungs of wild type (WT) and transgenic Tie2-PTX3 mice treated with bleomycin (BLM). For each image, the boxed area is shown at higher magnification in the right panel. Scale bar $=100 \mu \mathrm{m}$; scale bar of magnified images $=200 \mu \mathrm{m}$. (B) Score quantification of the $\alpha$ SMA immunostaining. $\alpha$ SMA immuno-reactivity in perivascular and peri-bronchiolar areas was excluded from the quantification. (C) qPCR analysis on lung extracts for the expression of collagen subunits and Acta2 mRNA. $N=$ 5-8 mice/group; ${ }^{*} P<0.05,{ }^{* \star} \mathrm{p}<0.01,{ }^{* \star *} \mathrm{p}<0.001$

female animals (31). On the other hand, these mice may show different responses under defined experimental conditions characterized by the involvement of the innate immune arm [reviewed in $(23,35,36)]$. BLM was administered intratracheal to Ptx3 null mice and lung fibrosis was followed in parallel to that occurring in WT and Tie2-PTX3 animals. As shown in Figure 5A, BLM treatment caused a dramatic decrease of the lifespan of $P t x 3^{-/-}$mice, with 4 out of 8 mice dying at day 14 and no survival occurring at day 21 after treatment. At variance, no animal death was observed for BLM-treated WT and Tie2-PTX3 mice. Accordingly, trichrome staining of the lung sections and quantification of fibrotic areas confirmed a significant increase of fibrotic/scar tissue at day 14 in $\mathrm{PTX}^{-/-}$mice when compared to WT and Tie2-PTX3 animals (Figures 5B, C).

\section{DISCUSSION}

Hyper-proliferating fibroblasts/myofibroblasts and augmented deposition of ECM are typical features of IPF and the main cause of lung architecture alterations underlying the loss of respiratory function (6). This is paralleled by an inflammatory response whose contribution to IPF has long been debated (37) and in some cases remains controversial $(38,39)$. For instance, treatment of IPF patients with steroids reduces inflammation in the lung but does not improve survival nor clinical outcome (40, 41 ), and a clinical trial based on immune-suppression was discontinued due to increased hospitalization and death (42).

PTX3 is a component of the humoral arm of the innate immunity. Even though its expression in human tissues is usually associated with inflammation, both pro-inflammatory and inflammation-limiting properties have been reported in preclinical models of disease, and a possible dual role has been unveiled in physiological and pathological settings $(35,43,44)$. On one side, PTX3 generally exhibits protective antibody-like functions and promotes tissue repair via matrix remodeling and modulation of the inflammatory response. On the other hand, potential damaging effects have been ascribed to PTX3 due to its capacity to induce endothelial dysfunction (45), exacerbated complement activation and inflammation $(44,46,47)$. 
A
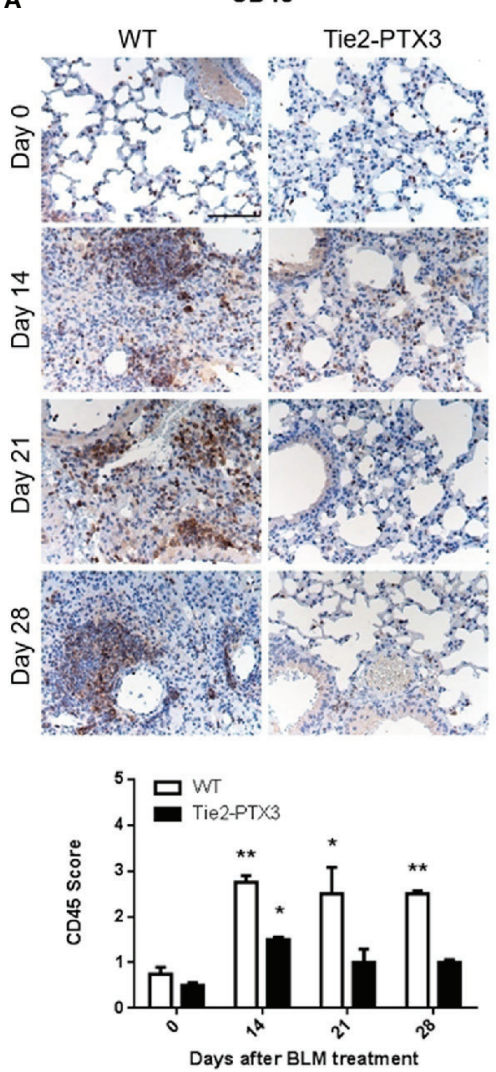

B
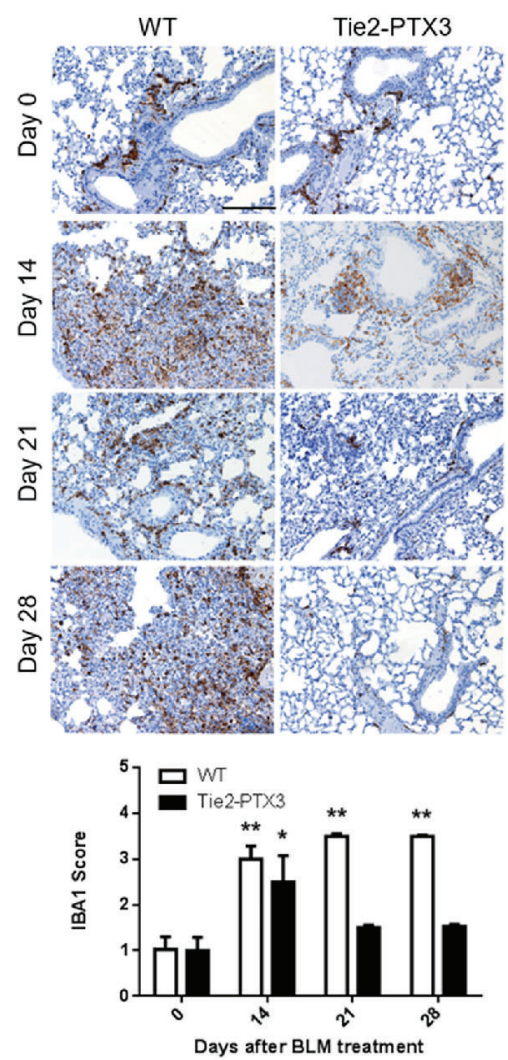

FIGURE 4 | Stromal PTX3 overexpression prevents immune infiltration in BLM-induced lung fibrosis. CD45 (A) and IBA1 (B) levels in the lungs of wild type (WT) and transgenic Tie2-PTX3 mice treated with bleomycin (BLM) were assessed by immunohistochemistry and quantified by scoring the immunostaining. $\mathrm{N}=5-8$ mice/ group; scale bar = $100 \mu \mathrm{m}$ (A), $200 \mu \mathrm{m}$ (B); ${ }^{*} \mathrm{P}<0.05 ;{ }^{* *} \mathrm{p}<0.01$

In inflammatory/injury settings, neutrophils are among the first leukocytes to be recruited. Once activated, they secrete their content of "ready to release" PTX3 that partially remains associated with neutrophil extracellular traps (NETs) $(48,49)$. On the other hand, PTX3 locally released by activated leukocytes may impair leukocyte rolling on endothelium, thus attenuating the recruitment of neutrophils, regulating inflammation, and reducing tissue damage in murine models of acute lung injury, pleurisy, and mesenteric inflammation (50).

Under physiological conditions, the expression levels of PTX3 are low in the lungs of healthy mice and can be modulated depending on the severity and duration of the damaging agent $(31,51-53)$. In this study we investigated the expression of PTX3 in a BLM-induced murine model of lung fibrosis with the aim to define its role in this pathological context.

In keeping with previous observations in preclinical models of lung fibrosis and in lung tissue from IPF patients (54), PTX3 expression rapidly increases in the lungs of BLM-treated animals both at mRNA and protein levels. This upregulation is transient, reaches a peak at 14 days after treatment to decrease to physiological levels thereafter. Thus, PTX3 upregulation represents an early event in response to the fibrotic insult, unable to restrain and control the onset of BLM-induced fibrosis in the lungs, that continues till day 28 after treatment.

Two distinct experimental approaches pointed to a protective role for PTX3 in this model of PF. In a first set of experiments, PTX3 overexpression in transgenic Tie2-PTX3 animals, which results in the accumulation of PTX3 in the lung stroma (32), was able to limit the formation of fibrotic tissue in the lungs, with reduced activation of fibroblasts and ECM deposition. Moreover, the infiltration of immune $\mathrm{CD} 45^{+}$cells was reduced in Tie2PTX3 lungs that showed a dramatic decrease in infiltrating $\mathrm{IBA}^{+}$macrophages when compared to WT animals, with moderate or no major differences in infiltrating neutrophils and $\mathrm{T}$ lymphocytes at the experimental points investigated. These observations are in line with the critical regulatory activities exerted by macrophages during all the steps of fibrosis onset and repair $(55,56)$. The protective effect of PTX3 on lung fibrosis was confirmed in a second set of experiments performed on $P t x 3^{-/-}$animals in which PTX3 deficiency caused an increased deposition of fibrotic tissue and a rapid animal death following BLM administration.

Even though the molecular mechanisms at the basis of this impact of PTX3 on PF remain to be elucidated, previous 
A

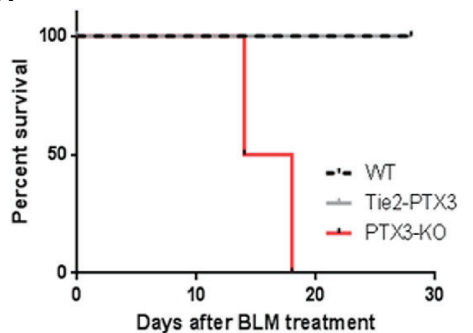

C

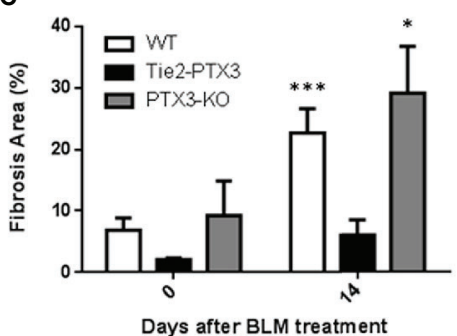

B

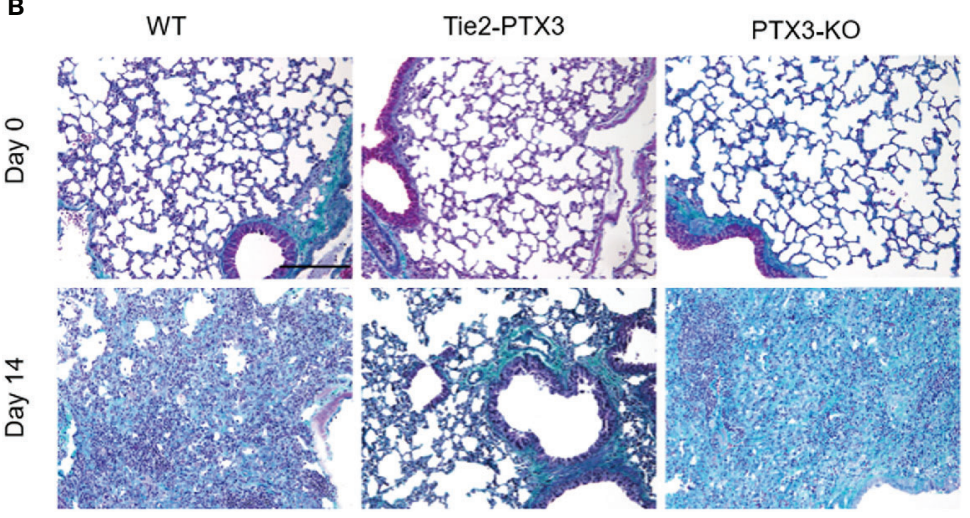

FIGURE 5 | Ptx3 knockdown increases the deposition of fibrotic tissue and a rapid animal death in BLM-induced lung fibrosis. (A) Kaplan-Meier survival curve of

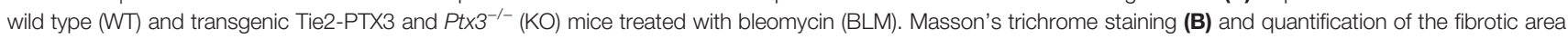
(C) performed on lungs at day 0 and day 14 after treatment. $N=5-8$ mice/group; scale bar $=100 \mu \mathrm{m}$; ${ }^{*}<<0.05,{ }^{\star \star *} \mathrm{p}<0.001$.

experimental evidences suggest that its accumulation in the pulmonary stroma may modulate different biological processes, including the recruitment of immune cells $(50,57,58)$ and fibroblast activation $(22,36)$. This occurs via the interaction of PTX3 with growth factors, complement components, the haemostatic system and the fibrinolytic cascade. Indeed, PTX3 can bind to fibroblast growth factors (FGFs) and impair the FGF/ FGF receptor system $(22,24)$ which plays a relevant role in fibrosis (59) as well as in immune cell recruitment $(33,60)$. In vitro, the interaction of PTX3 with Fc $\gamma \mathrm{RI}$ has been shown to favor the differentiation of human and murine monocytes into fibrocytes, fibroblast-like cells expressing both haematopoietic and stromal cell markers frequently found in fibrotic lesions (54, 61). In the same context, the serum amyloid P component (SAP) was shown to play a fibrocyte-inhibitory activity stronger than PTX3 (54), and injections of SAP inhibited fibrosis in various mouse models of the disease $(62,63)$. Interestingly, SAP expression was almost absent in fibrotic areas, while PTX3 was widespread, thus suggesting that relative levels of SAP and PTX3 may have a significant role in fibrocyte differentiation at fibrotic sites (54).

In the acute lung injury, a strong activation of the innate immune system in the lungs is accompanied by the expression of PTX3. This pathological context is characterized by infiltration of neutrophils and increased production of nitric oxide and of tissue factor. It has been suggested that high levels of PTX3 activate the local innate immune system and play a protective role against lung insults (21, 51). Accordingly, $P t \times 3^{-/-}$mice are more susceptible to tissue damage after exposure to LPS (28). In addition, PTX3 can interact with fibrin and plasminogen under acidic conditions in damaged/ inflamed tissues, fostering the remodeling of the fibrin-rich matrix and tissue repair (64).

Overall, in this study we have reported the observational results of the effect of endogenous PTX3 modulation on lung fibrosis onset and phenotype. Intravenous or intraperitoneal treatment with recombinant PTX3 has resulted in beneficial outcomes in various experimental models of inflammatory diseases $(25,31,48,65-67)$. Thus, in a therapeutic perspective, it will be of importance to assess the effect of recombinant PTX3 to prevent fibrosis in BLM-treated mice. Our results and these future studies will pave the way for the characterization of the molecular players modulated by PTX3 in PF and for the design of PTX3-derived approaches to be used for the treatment of PF patients.

\section{DATA AVAILABILITY STATEMENT}

The raw data supporting the conclusions of this article will be made available by the authors, without undue reservation. 


\section{ETHICS STATEMENT}

The animal study was reviewed and approved by OPBA University of Brescia.

\section{AUTHOR CONTRIBUTIONS}

FM performed in vivo experiments. MB performed immunohistochemistry. AS, WV, and SG gave technical assistance. MP conceived the experimental plan and revised the paper. RR conceived and supervised the experiments, and wrote the paper. All authors contributed to the article and approved the submitted version.

\section{REFERENCES}

1. Bartczak K, Bialas AJ, Kotecki MJ, Gorski P, Piotrowski WJ. More than a Genetic Code: Epigenetics of Lung Fibrosis. Mol Diagn Ther (2020) 24 (6):665-81. doi: 10.1007/s40291-020-00490-7

2. Sauleda J, Nunez B, Sala E, Soriano JB. Idiopathic Pulmonary Fibrosis: Epidemiology, Natural History, Phenotypes. Med Sci (Basel) (2018) 6(4). doi: $10.3390 /$ medsci6040110

3. Diridollou T, Sohier L, Rousseau C, Angibaud A, Chauvin P, Gaignon T, et al. Idiopathic pulmonary fibrosis: Significance of the usual interstitial pneumonia (UIP) CT-scan patterns defined in new international guidelines. Respir Med Res (2020) 77:72-8. doi: 10.1016/j.resmer.2020.02.004

4. Raghu G, Collard HR, Egan JJ, Martinez FJ, Behr J, Brown KK, et al. An official ATS/ERS/JRS/ALAT statement: idiopathic pulmonary fibrosis: evidence-based guidelines for diagnosis and management. Am J Respir Crit Care Med (2011) 183(6):788-824. doi: 10.1164/rccm.2009-040GL

5. Lederer DJ, Martinez FJ. Idiopathic Pulmonary Fibrosis. N Engl J Med (2018) 379(8):797-8. doi: 10.1056/NEJMc1807508

6. Kuhn C, Mason RJ. Immunolocalization of SPARC, tenascin, and thrombospondin in pulmonary fibrosis. Am J Pathol (1995) 147(6):1759-69.

7. Laskin DL, Malaviya R, Laskin JD. Role of Macrophages in Acute Lung Injury and Chronic Fibrosis Induced by Pulmonary Toxicants. Toxicol Sci (2019) 168(2):287-301. doi: 10.1093/toxsci/kfy309

8. Misharin AV, Morales-Nebreda L, Reyfman PA, Cuda CM, Walter JM, McQuattie-Pimentel AC, et al. Monocyte-derived alveolar macrophages drive lung fibrosis and persist in the lung over the life span. J Exp Med (2017) 214(8):2387-404. doi: 10.1084/jem.20162152

9. Larson-Casey JL, Deshane JS, Ryan AJ, Thannickal VJ, Carter AB. Macrophage Aktl Kinase-Mediated Mitophagy Modulates Apoptosis Resistance and Pulmonary Fibrosis. Immunity (2016) 44(3):582-96. doi: 10.1016/j.immuni.2016.01.001

10. Gibbons MA, MacKinnon AC, Ramachandran P, Dhaliwal K, Duffin R, Phythian-Adams AT, et al. Ly6Chi monocytes direct alternatively activated profibrotic macrophage regulation of lung fibrosis. Am J Respir Crit Care Med (2011) 184(5):569-81. doi: 10.1164/rccm.201010-17190C

11. Bickelhaupt S, Erbel C, Timke C, Wirkner U, Dadrich M, Flechsig P, et al. Effects of CTGF Blockade on Attenuation and Reversal of Radiation-Induced Pulmonary Fibrosis. J Natl Cancer Inst (2017) 109(8). doi: 10.1093/jnci/djw339

12. Prasse A, Pechkovsky DV, Toews GB, Jungraithmayr W, Kollert F, Goldmann T, et al. A vicious circle of alveolar macrophages and fibroblasts perpetuates pulmonary fibrosis via CCL18. Am J Respir Crit Care Med (2006) 173(7):78192. doi: 10.1164/rccm.200509-1518OC

13. Pulichino AM, Wang IM, Caron A, Mortimer J, Auger A, Boie Y, et al. Identification of transforming growth factor beta1-driven genetic programs of acute lung fibrosis. Am J Respir Cell Mol Biol (2008) 39(3):324-36. doi: 10.1165/rcmb.2007-0186OC

14. Shvedova AA, Kisin ER, Mercer R, Murray AR, Johnson VJ, Potapovich AI, et al. Unusual inflammatory and fibrogenic pulmonary responses to singlewalled carbon nanotubes in mice. Am J Physiol Lung Cell Mol Physiol (2005) 289(5):L698-708. doi: 10.1152/ajplung.00084.2005

\section{FUNDING}

This work was supported by Associazione Italiana per la Ricerca sul Cancro (IG 2019 no. 23116 to MP and IG 2019 no. 23151 to RR). FM was supported by Fondazione Veronesi Fellowship.

\section{SUPPLEMENTARY MATERIAL}

The Supplementary Material for this article can be found online at: https://www.frontiersin.org/articles/10.3389/fimmu.2021. 617671/full\#supplementary-material

15. Moore BB, Hogaboam CM. Murine models of pulmonary fibrosis. Am J Physiol Lung Cell Mol Physiol (2008) 294(2):L152-60. doi: 10.1152/ ajplung.00313.2007

16. Izbicki G, Segel MJ, Christensen TG, Conner MW, Breuer R. Time course of bleomycin-induced lung fibrosis. Int J Exp Pathol (2002) 83(3):111-9. doi: 10.1046/j.1365-2613.2002.00220.x

17. Muggia FM, Louie AC, Sikic BI. Pulmonary toxicity of antitumor agents Cancer Treat Rev (1983) 10(4):221-43. doi: 10.1016/0305-7372(83)90012-9

18. Phan SH, Thrall RS, Ward PA. Bleomycin-induced pulmonary fibrosis in rats: biochemical demonstration of increased rate of collagen synthesis. Am Rev Respir Dis (1980) 121(3):501-6. doi: 10.1164/arrd.1980.121.3.501

19. Snider GL, Hayes JA, Korthy AL. Chronic interstitial pulmonary fibrosis produced in hamsters by endotracheal bleomycin: pathology and stereology. Am Rev Respir Dis (1978) 117(6):1099-108. doi: 10.1164/arrd.1978.117.6.1099

20. Thrall RS, McCormick JR, Jack RM, McReynolds RA, Ward PA. Bleomycininduced pulmonary fibrosis in the rat: inhibition by indomethacin. Am J Pathol (1979) 95(1):117-30.

21. Balhara J, Koussih L, Zhang J, Gounni AS. Pentraxin 3: an immuno-regulator in the lungs. Front Immunol (2013) 4:127. doi: 10.3389/fimmu.2013.00127

22. Giacomini A, Ghedini GC, Presta M, Ronca R. Long pentraxin 3: A novel multifaceted player in cancer. Biochim Biophys Acta (2018) 1869(1):53-63. doi: 10.1016/j.bbcan.2017.11.004

23. Doni A, Stravalaci M, Inforzato A, Magrini E, Mantovani A, Garlanda C, et al. The Long Pentraxin PTX3 as a Link Between Innate Immunity, Tissue Remodeling, and Cancer. Front Immunol (2019) 10:712. doi: 10.3389/ fimmu.2019.00712

24. Presta M, Foglio E, Churruca Schuind A, Ronca R. Long Pentraxin-3 Modulates the Angiogenic Activity of Fibroblast Growth Factor-2. Front Immunol (2018) 9:2327. doi: 10.3389/fimmu.2018.02327

25. Moalli F, Doni A, Deban L, Zelante T, Zagarella S, Bottazzi B, et al. Role of complement and $\mathrm{Fc}\{$ gamma\} receptors in the protective activity of the long pentraxin PTX3 against Aspergillus fumigatus. Blood (2010) 116(24):5170-80. doi: 10.1182/blood-2009-12-258376

26. Deban L, Jarva H, Lehtinen MJ, Bottazzi B, Bastone A, Doni A, et al. Binding of the long pentraxin PTX3 to factor $\mathrm{H}$ : interacting domains and function in the regulation of complement activation. J Immunol (2008) 181(12):8433-40. doi: 10.4049/jimmunol.181.12.8433

27. Han B, Ma X, Zhang J, Zhang Y, Bai X, Hwang DM, et al. Protective effects of long pentraxin PTX3 on lung injury in a severe acute respiratory syndrome model in mice. Lab Investigation J Tech Methods Pathol (2012) 92(9):1285-96. doi: 10.1038/labinvest.2012.92

28. Okutani D, Han B, Mura M, Waddell TK, Keshavjee S, Liu M. High-volume ventilation induces pentraxin 3 expression in multiple acute lung injury models in rats. Am J Physiol Lung Cell Mol Physiol (2007) 292(1):L144-53. doi: 10.1152/ajplung.00002.2006

29. Zhang J, Shan L, Koussih L, Redhu NS, Halayko AJ, Chakir J, et al. Pentraxin 3 (PTX3) expression in allergic asthmatic airways: role in airway smooth muscle migration and chemokine production. PLoS One (2012) 7(4):e34965 doi: 10.1371/journal.pone.0034965 
30. Diamandis EP, Goodglick L, Planque C, Thornquist MD. Pentraxin-3 is a novel biomarker of lung carcinoma. Clin Cancer Res (2011) 17(8):2395-9. doi: 10.1158/1078-0432.CCR-10-3024

31. Garlanda C, Hirsch E, Bozza S, Salustri A, De Acetis M, Nota R, et al. Nonredundant role of the long pentraxin PTX3 in anti-fungal innate immune response. Nature (2002) 420(6912):182-6. doi: 10.1038/nature01195

32. Ronca R, Giacomini A, Di Salle E, Coltrini D, Pagano K, Ragona L, et al. LongPentraxin 3 Derivative as a Small-Molecule FGF Trap for Cancer Therapy. Cancer Cell (2015) 28(2):225-39. doi: 10.1016/j.ccell.2015.07.002

33. Ronca R, Tamma R, Coltrini D, Ruggieri S, Presta M, Ribatti D. Fibroblast growth factor modulates mast cell recruitment in a murine model of prostate cancer. Oncotarget (2017) 8(47):82583-92. doi: 10.18632/oncotarget.19773

34. Matarazzo S, Melocchi L, Rezzola S, Grillo E, Maccarinelli F, Giacomini A, et al. Long Pentraxin-3 Follows and Modulates Bladder Cancer Progression. Cancers (2019) 11(9). doi: 10.3390/cancers11091277

35. Mantovani A, Valentino S, Gentile S, Inforzato A, Bottazzi B, Garlanda C. The long pentraxin PTX3: a paradigm for humoral pattern recognition molecules. Ann N Y Acad Sci (2013) 1285:1-14. doi: 10.1111/nyas.12043

36. Doni A, Garlanda C, Mantovani A. Innate immunity, hemostasis and matrix remodeling: PTX3 as a link. Semin Immunol (2016) 28(6):570-7. doi: 10.1016/ j.smim.2016.10.012

37. McLean-Tooke A, Moore I, Lake F. Idiopathic and immune-related pulmonary fibrosis: diagnostic and therapeutic challenges. Clin Trans Immunol (2019) 8(11):e1086. doi: 10.1002/cti2.1086

38. Gauldie J. Pro: Inflammatory mechanisms are a minor component of the pathogenesis of idiopathic pulmonary fibrosis. Am J Respir Crit Care Med (2002) 165(9):1205-6. doi: 10.1164/rccm.2202054

39. Strieter RM. Con: Inflammatory mechanisms are not a minor component of the pathogenesis of idiopathic pulmonary fibrosis. Am J Respir Crit Care Med (2002) 165(9):1206-7; discussion 7-8. doi: 10.1164/rccm.2202055

40. Grijm K, Verberne HJ, Krouwels FH, Weller FR, Jansen HM, Bresser P. Semiquantitative $67 \mathrm{Ga}$ scintigraphy as an indicator of response to and prognosis after corticosteroid treatment in idiopathic interstitial pneumonia. J Nucl Med (2005) 46(9):1421-6.

41. Pereira CA, Malheiros T, Coletta EM, Ferreira RG, Rubin AS, Otta JS, et al. Survival in idiopathic pulmonary fibrosis-cytotoxic agents compared to corticosteroids. Respir Med (2006) 100(2):340-7. doi: 10.1016/j.rmed.2005.05.008

42. Raghu G, Anstrom KJ, King TE Jr., Lasky JA, Martinez FJ. Prednisone, azathioprine, and N-acetylcysteine for pulmonary fibrosis. $N$ Engl J Med (2012) 366(21):1968-77. doi: 10.1056/NEJMoa1113354

43. Bonacina F, Baragetti A, Catapano AL, Norata GD. Long pentraxin 3: experimental and clinical relevance in cardiovascular diseases. Mediators Inflamm (2013) 2013:725102. doi: 10.1155/2013/725102

44. Magrini E, Mantovani A, Garlanda C. The Dual Complexity of PTX3 in Health and Disease: A Balancing Act? Trends Mol Med (2016) 22(6):497-510. doi: 10.1016/j.molmed.2016.04.007

45. Foo SS, Chen W, Taylor A, Sheng KC, Yu X, Teng TS, et al. Role of pentraxin 3 in shaping arthritogenic alphaviral disease: from enhanced viral replication to immunomodulation. PLoS Pathog (2015) 11(2):e1004649. doi: 10.1371/ journal.ppat.1004649

46. Inforzato A, Doni A, Barajon I, Leone R, Garlanda C, Bottazzi B, et al. PTX3 as a paradigm for the interaction of pentraxins with the complement system. Semin Immunol (2013) 25(1):79-85. doi: 10.1016/j.smim.2013.05.002

47. Souza DG, Soares AC, Pinho V, Torloni H, Reis LF, Teixeira MM, et al. Increased mortality and inflammation in tumor necrosis factor-stimulated gene-14 transgenic mice after ischemia and reperfusion injury. Am J Pathol (2002) 160(5):1755-65. doi: 10.1016/s0002-9440(10)61122-4

48. Jaillon S, Peri G, Delneste Y, Fremaux I, Doni A, Moalli F, et al. The humoral pattern recognition receptor PTX3 is stored in neutrophil granules and localizes in extracellular traps. J Exp Med (2007) 204(4):793-804. doi: 10.1084/jem.20061301

49. Daigo K, Yamaguchi N, Kawamura T, Matsubara K, Jiang S, Ohashi R, et al. The proteomic profile of circulating pentraxin 3 (PTX3) complex in sepsis demonstrates the interaction with azurocidin 1 and other components of neutrophil extracellular traps. Mol Cell Proteomics MCP (2012) 11(6):M111 015073. doi: 10.1074/mcp.M111.015073

50. Deban L, Russo RC, Sironi M, Moalli F, Scanziani M, Zambelli V, et al. Regulation of leukocyte recruitment by the long pentraxin PTX3. Nat Immunol (2010) 11(4):328-34. doi: 10.1038/ni.1854
51. He X, Han B, Liu M. Long pentraxin 3 in pulmonary infection and acute lung injury. Am J Physiol Lung Cell Mol Physiol (2007) 292(5):L1039-49. doi: 10.1152/ajplung.00490.2006

52. Pauwels NS, Bracke KR, Maes T, Van Pottelberge GR, Garlanda C, Mantovani A, et al. Cigarette smoke induces PTX3 expression in pulmonary veins of mice in an IL-1 dependent manner. Respir Res (2010) 11:134. doi: 10.1186/1465-9921-11-134

53. Han B, Mura M, Andrade CF, Okutani D, Lodyga M, dos Santos CC, et al. TNFalpha-induced long pentraxin PTX3 expression in human lung epithelial cells via JNK. J Immunol (2005) 175(12):8303-11. doi: 10.4049/ jimmunol.175.12.8303

54. Pilling D, Cox N, Vakil V, Verbeek JS, Gomer RH. The long pentraxin PTX3 promotes fibrocyte differentiation. PLoS One (2015) 10(3):e0119709. doi: 10.1371/journal.pone.0119709

55. Wynn TA, Barron L. Macrophages: master regulators of inflammation and fibrosis. Semin Liver Dis (2010) 30(3):245-57. doi: 10.1055/s-0030-1255354

56. Wynn TA, Vannella KM. Macrophages in Tissue Repair, Regeneration, and Fibrosis. Immunity (2016) 44(3):450-62. doi: 10.1016/j.immuni.2016.02.015

57. Bonavita E, Gentile S, Rubino M, Maina V, Papait R, Kunderfranco P, et al. PTX3 is an extrinsic oncosuppressor regulating complement-dependent inflammation in cancer. Cell (2015) 160(4):700-14. doi: 10.1016/j.cell.2015.01.004

58. Annese T, Ronca R, Tamma R, Giacomini A, Ruggieri S, Grillo E, et al. PTX3 Modulates Neovascularization and Immune Inflammatory Infiltrate in a Murine Model of Fibrosarcoma. Int J Mol Sci (2019) 20(18). doi: 10.3390/ijms20184599

59. Guzy RD, Li L, Smith C, Dorry SJ, Koo HY, Chen L, et al. Pulmonary fibrosis requires cell-autonomous mesenchymal fibroblast growth factor (FGF) signaling. J Biol Chem (2017) 292(25):10364-78. doi: 10.1074/ jbc.M117.791764

60. Presta M, Andres G, Leali D, Dell'Era P, Ronca R. Inflammatory cells and chemokines sustain FGF2-induced angiogenesis. Eur Cytokine Netw (2009) 20 (2):39-50. doi: 10.1684/ecn.2009.0155

61. Reilkoff RA, Bucala R, Herzog EL. Fibrocytes: emerging effector cells in chronic inflammation. Nat Rev Immunol (2011) 11(6):427-35. doi: 10.1038/ nri2990

62. Pilling D, Roife D, Wang M, Ronkainen SD, Crawford JR, Travis EL, et al. Reduction of bleomycin-induced pulmonary fibrosis by serum amyloid $\mathrm{P}$. J Immunol (2007) 179(6):4035-44. doi: 10.4049/jimmunol.179.6.4035

63. Murray LA, Rosada R, Moreira AP, Joshi A, Kramer MS, Hesson DP, et al. Serum amyloid $\mathrm{P}$ therapeutically attenuates murine bleomycin-induced pulmonary fibrosis via its effects on macrophages. PLoS One (2010) 5(3): e9683. doi: 10.1371/journal.pone.0009683

64. Doni A, Musso T, Morone D, Bastone A, Zambelli V, Sironi M, et al. An acidic microenvironment sets the humoral pattern recognition molecule PTX3 in a tissue repair mode. J Exp Med (2015) 212(6):905-25. doi: 10.1084/ jem. 20141268

65. Gaziano R, Bozza S, Bellocchio S, Perruccio K, Montagnoli C, Pitzurra L, et al. Anti-Aspergillus fumigatus efficacy of pentraxin 3 alone and in combination with antifungals. Antimicrobial Agents Chemother (2004) 48(11):4414-21. doi: 10.1128/AAC.48.11.4414-4421.2004

66. Paroni M, Moalli F, Nebuloni M, Pasqualini F, Bonfield T, Nonis A, et al. Response of CFTR-deficient mice to long-term chronic Pseudomonas aeruginosa infection and PTX3 therapy. J Infect Dis (2013) 208(1):130-8. doi: 10.1093/infdis/jis636

67. Moalli F, Paroni M, Veliz Rodriguez T, Riva F, Polentarutti N, Bottazzi B, et al. The therapeutic potential of the humoral pattern recognition molecule PTX3 in chronic lung infection caused by Pseudomonas aeruginosa. J Immunol (2011) 186(9):5425-34. doi: 10.4049/jimmunol.1002035

Conflict of Interest: The authors declare that the research was conducted in the absence of any commercial or financial relationships that could be construed as a potential conflict of interest.

Copyright (C) 2021 Maccarinelli, Bugatti, Churruca Schuind, Ganzerla, Vermi, Presta and Ronca. This is an open-access article distributed under the terms of the Creative Commons Attribution License (CC BY). The use, distribution or reproduction in other forums is permitted, provided the original author(s) and the copyright owner(s) are credited and that the original publication in this journal is cited, in accordance with accepted academic practice. No use, distribution or reproduction is permitted which does not comply with these terms. 